\title{
OS USOS DA CATEGORIA TRABALHO NA EDUCAÇÃO FÍSICA.
}

\author{
Carlos Herold Junior \\ Professor Adjunto do Departamento de Pedagogia \\ UNICENTRO - Guarapuava, PR. \\ carlosherold@hotmail.com
}

\section{RESUMO:}

O objetivo deste artigo é evidenciar presença do debate relativo à centralidade do trabalho na área de educação física. Para isso, dividimos a análise em três partes: na primeira, mostramos como alguns autores da educação física afirmam a importância ou a irrelevância do mundo do trabalho para a área; na segunda, defendemos que uma análise do trabalho feita baseada em Marx, Kosik e Lukács oferece possibilidades para que o trabalho seja assumido de forma mais crítica para o estudo da educação da corporalidade humana; na terceira, como conclusão, elencamos algumas conseqüências analíticas que podem ser notadas a partir da assunção do trabalho como fomentador de estudos e análises na educação física. Como principal resultado, notamos que uma consideração crítica das transformações produtivas que ocorrem na atualidade pode lançar novas e relevantes problemáticas aos estudiosos da educação física.

Palavras-chave: Trabalho, educação física, educação, corpo.

\section{USES OF LABOUR CATEGORY MADE IN PHYSICAL EDUCATION.}

\begin{abstract}
:
The aim of this article is to put in evidence the labor centrality issue for physical education. For that, we divided the study in three main parts: firstly, we show how some physical education authors state both the relevance or the uselessness of the labor for their field; after, we support that regarding labor based on Marx, Kosik and Lukács analysis offers some possibilities to study in a more critic way the corporeality and its education; in the third part, we specify some results that might be took in consideration when labor is used as point of departure for educational analysis. As a main conclusion, we could verify that if the productive transformations become seriously and critically considered they can raise new and important issues for physical education teachers.
\end{abstract}

Key-words: labor, physical education, education, body.

\section{INTRODUÇÃO}

Com as reordenações do capitalismo, oriundas de mais uma crise que assolou o modo de produção a partir da década de 70 , o debate sobre a validade e a centralidade da categoria trabalho ganhou força nas ciências humanas e na filosofia, sobretudo naquelas linhas de pesquisa que buscavam um posicionamento de crítica frente às relações sociais pautadas na exploração do trabalho.

A base do surgimento do debate foi construída na absorção por parte dos processos produtivos, das tecnologias da informação que, apesar das discordâncias sobre os impactos da "novas tecnologias", colocaram a discussão sobre os processos exploratórios do capital em relação ao trabalho em outro patamar, qualitativamente diferente. 
Com essas transformações à frente, os teóricos trataram de avaliar, então, a validade de se estudar as transformações do mundo do trabalho como fomentadora de questões para reflexão nos mais diferentes domínios da vida social, cultural e política.

Este estudo, assim, tem como objetivo evidenciar que esse debate também impactou as discussões concernentes à educação física e à corporeidade. Temos como intenção, também, endossar a importância dessa problemática, mostrando que a consideração crítica da categoria trabalho pode contornar os limites oriundos tanto da desconsideração, quanto da consideração limitada da análise do mundo do trabalho para a reflexão das questões educativas.

Para isso, dividimos o artigo em três momentos: no primeiro, apresentamos uma compreensão da importância da categoria trabalho, baseada nas análises de Marx, Lukács e Kosik; no segundo, analisamos a maneira como o debate sobre a centralidade do trabalho aparece em alguns estudos da área de educação física; na terceira parte, à guisa de conclusão, esboçamos alguns elementos analíticos para colaborar com que o referencial do trabalho seja mais largamente utilizado nos estudos referentes à educação da corporalidade humana.

\section{1 - O mundo do trabalho como lugar para se pensar as questões da contemporaneidade.}

As posições contrárias à consideração do trabalho têm como base a refutação de posicionamentos que advogavam uma derivação automática e/ou mecânica entre as transformações do trabalho e as transformações das dimensões sociais, políticas e culturais da sociedade. Essa refutação é importante, porém ela deve ser detidamente analisada para evitar que uma consideração mais precisa do mundo do trabalho não signifique simplesmente abandonar as questões concernentes às transformações produtivas da sociedade. Esse abandono é tão criticável quanto afirmar que é a economia a "base" das superestruturas. Kosik (1970), observa que as considerações limitantes do trabalho baseiam-se no que ele chama de fator econômico. Ou seja, tratava-se de encontrar um fator econômico quando do estudo de uma obra literária, por exemplo, e explicá-la, assim, pela "economia".

Propondo refletir sobre a contemporaneidade, Kosik (1970) diz que a idéia de sistema econômico, "representando a unidade e a conexão de todas as esferas da vida social" (p.79), diferentemente do entendimento baseado no fator econômico, considera a totalidade das relações sociais como "produção", como "práxis humana", na qual o trabalho tem um lugar importante. Essa reflexão procura, assim, assumir que a consideração do trabalho, da produção social da existência, não deve ser reduzida a um dado econômico. Ela é um amplo processo, impossível de ser captado individualmente, mas mesmo assim concreto em toda sua historicidade.

Seguindo o caminho dessas reflexões, encontramos a obra de Lukács $(1979,2004)$, para quem a reflexão sobre o lugar do trabalho é de grande relevância ${ }^{1}$. Para ele, é possível ver a construção das potencialidades humanas no e pelo trabalho, desde que a diferença entre trabalho como relação entre homem e natureza, e o trabalho abstrato sobre a égide da reprodução do capital, seja considerada. Lukács intenciona explicar como utilizar o trabalho como um momento importante da sociedade, sem cair em mistificações e simplismos economicistas.

O trabalho, não entendido na sua dimensão especificamente capitalista, mas como atividade humana presente em todos momentos da história, proporciona um encontro de elementos díspares, isolados e que somente socialmente podem se encontrar, dando início 
ao ser social, diferente, porém dependente do ser natural. É por isso que "O trabalho pode ser considerado, pois, como fenômeno originário, como modelo do ser social..." (p.59) É o trabalho o ponto sobre o qual a transformação humana e a complexificação social ocorrem.

O trabalho é um dos momentos em que o caráter práxico da produção humana mais claramente se apresenta. E esse caráter possibilita que, em determinados desenvolvimentos sociais, a atividade laboral acabe desviando-se dessa própria práxis quando ela se torna determinada por relações sociais que separam o trabalhador dos produtos que produz, tanto pelo incremento da divisão social do trabalho quanto pela própria apropriação privada dos meios e dos produtos. Por isso, o trabalho nunca deve ser usado diretamente como meio para a compreensão da sociedade, afinal, a partir do próprio trabalho, outras problemáticas intervêm de forma intensa, não podendo ser desconsideradas. Disso deriva que, mesmo assumindo o trabalho como categoria central de sua análise, são justamente as características do trabalho como elemento fundante que impossibilitam que haja um paralelismo absoluto entre o desenvolvimento histórico da sociedade e o seu desenvolvimento teórico. Essa advertência é válida para a própria base produtiva da sociedade:

\begin{abstract}
Antes de mais nada, aparece no valor, enquanto categoria social, a base elementar do ser social: o trabalho. A ligação deste com as funções sociais do valor revela os princípios estruturadores fundamentais do ser social, que derivam do ser natural do homem e, ao mesmo tempo, do seu intercâmbio orgânico com a natureza, um processo no qual cada momento - a conexão ontológica ineliminável entre a insuperabilidade última dessa base material e sua constante e crescente superação (tanto extensiva quanto intensiva), ou seja, sua transformação no sentido da socialidade pura - revela tratar-se de um processo que culmina em categorias que, como é o caso do próprio valor, já se separaram inteiramente da materialidade natural (Lukács, 1979, p.48).
\end{abstract}

Vale esclarecer também que a própria concepção de produção para Marx, além do sentido econômico, concreto de produção da existência, possui também um sentido ontológico mais largo. Lukács (1979) verifica que, mesmo nos estágios mais primitivos da sociedade, ela nunca esteve ligada à mera reprodução biológica, exclusivamente: “... somente quando o caráter predominante da produção no processo de surgimento e modificação da distribuição é colocado de modo claro é que se torna possível compreender corretamente a relação entre econômico e extra-econômico" (p.73).

Para Lukács, essa consideração do trabalho oferece a base para o desenvolvimento das ciências, que partindo de questões concretas relacionadas com a resolução de problemas imediatos, vão atingindo níveis de abstração cada vez maiores. Obviamente que o retorno e o impacto sobre a prática, sobre a liberdade de escolha entre alternativas existentes e para a própria visualização de nova alternativas, tudo isso faz da ciência e da filosofia, por mais abstratas que venham a ser, atividades práticas. Com o processo de escolhas entre alternativas e construção de causalidades cada vez mais complexas, a ciência acaba surgindo como resposta da necessidade de sistematizar as reflexões que são feitas na hora de optar entre as alternativas postas pelas condições concretas a cada momento.

É nesse ponto que Lukács adverte contra os riscos de se fetichizar a razão. Esse reconhecimento, ausente no "marxismo vulgar", também não é encontrado no que Lukács (1979) chama de "filosofias idealistas-burguesas". Tanto uma quanto as outras estabelecem relações antinômicas entre o material e o espiritual, entre o natural e o social, não 
conseguindo, dessa forma, apreender os nexos específicos do ser social. Afirma Lukács (1979):

[...] essa dialética é incompreensível para quem não é capaz de colocar-se acima daquela visão primitiva da realidade, segundo a qual só se reconhece como materialidade, aliás, como objetividade em-si, a coisalidade, enquanto se atribui todas as demais formas de objetividade (relações, conexões etc) assim como todos os reflexos da realidade que se apresentam imediatamente como produtos do pensamento[...], a uma suposta atividade autônoma da consciência (p.48).

Para o filósofo, só podemos escapar da capitulação frente às particularidades objetivas e/ou subjetivas, reconhecendo a prioridade ontológica do "material" na constituição do ser social. E ele justifica esse ponto, ao verificar que tomar o trabalho como parâmetro de análise, não quer dizer reduzir a reflexão à atividade laboral em si, mas considerar o seu caráter social. Mesmo reconhecendo a importância dos atos particulares Lukács (2004) acrescenta: "Mesmo a mais complexa economia é uma resultante de posições teleológicas individuais, de suas realizações, ambas sob a forma de alternativas. [...] Mas, a partir de um certo nível, esta totalidade não pode ser captada pelos sujeitos econômicos individuais" (p.137).

O relacionamento entre totalidade e particularidade recebe nuances importantes para a temática deste estudo quando Lukács nota que, com o desenvolvimento do ser social e o estabelecimento de relações mais complexas entre o social e o natural, o próprio ser biológico, antes considerado um todo em sua particularidade, passa a fazer, pelo trabalho, parte de um todo mais complexo quando integra o ser social que, mesmo superando a natureza, não existe sem a sua base.

Marx, afirma Lukács (1979, 2004), ao assumir a centralidade do trabalho como fonte de socialização e construção do homem pelo próprio homem, observa que a riqueza produzida e as forças produtivas são objetivações do desenvolvimento do domínio do homem sobre suas forças naturais, socializando-as e usando-as para o contínuo estabelecimento das relações entre cada indivíduo, sociedade e a natureza, em um grande processo só socialmente possível. Além disso, é daí que surge e se desenvolve, a possibilidade de cultivo e de respeito às particularidades, cada vez mais reconhecidas à medida que a sociabilidade se estende. A consideração do processo social de produção possibilita um ponto de partida para a análise social, sem que esse ponto seja válido de forma homogênea para todas as épocas e sociedades, sendo essa diferença que valoriza a importância de outras dimensões a serem utilizadas como fonte de pesquisa que, apesar de variadas e específicas, compõe a totalidade social proporcionada pelo trabalho.

\section{2 - Os diferentes entendimentos sobre mundo do trabalho na Educação Física}

$\mathrm{Na}$ área de Educação Física, um resultado interessante produzido pelas mudanças no mundo do trabalho, a partir das décadas de 70 e 80 , bem como por uma determinada forma de análise, foi o fato de o trabalho ter sido excluído das reflexões. Se antes, conjugado com a categoria de luta de classes, ele serviu de base para as constatações críticas dos professores, esses, ao observarem a "submissão" da Educação Física e da corporeidade às suas exigências, elaboraram um conjunto de reflexões que redundou em uma pedagogia que não mais fosse "instrumentalizada" pelo trabalho. De acordo com esse 
raciocínio, ao fato de o trabalho ter explorado as forças expressivas do corpo, somava-se que na atualidade, com o surgimento das tecnologias flexíveis, o trabalho estaria assumindo cada vez mais uma feição "intelectualizada".

$\mathrm{Na}$ Educação Física, as referências ao mundo do trabalho e o seu impacto nas discussões sobre a relação entre essa disciplina e a sociedade são poucas e geralmente carecem de uma elaboração mais detida em torno da temática. Bracht (1992), defende as idéias que primam pela perda da importância do trabalho para entender o corpo e a educação física:

Entendo que as mudanças a nível do processo produtivo e do processo de qualificação do trabalho, diminuíram a importância direta da Educação Física neste processo (aptidão física e habilidades motoras decrescem em importância para o processo produtivo, são cada vez menos solicitadas no trabalho). A reprodução da força de trabalho por sua vez, se dá muito mais através de uma cada vez mais necessária recuperação psíquica (Bracht, 1992, p.49).

Completando o raciocínio, o autor conclui que, para uma Educação Física "autônoma", deve a "referência básica ou imediata deixar de ser o mundo do trabalho, e passar a ser o mundo do não-trabalho, o lazer" (Bracht, 1992, p.49).

Silva (2001) também lança mão do mundo do trabalho modo secundário para corroborar suas reflexões. A autora deixa claro o entendimento da importância do trabalho na relação do homem com a natureza e a necessidade de uma "sociedade emancipada" (p.126) para que essa relação se efetive de forma reconciliada. Ela apresenta essas idéias verificando que a expropriação do corpo pela ciência ocorre "[...] tal qual no mundo do trabalho, sobre a 'livre disposição de sua força de trabalho', só que nesse caso, não seria em favor de um patrão, mas sim do sistema médico" (p. 52).

Apesar de a questão da relação entre corporeidade e trabalho não ser o objetivo do trabalho de Silva (2001), pode-se ver que além do ponto acima referido, ela também tece considerações que vão ao encontro das reflexões de Bracht (1992). Sobre as transformações no mundo do trabalho e a presença do corpo, afirma a autora:

As características do mundo do trabalho estariam sendo alteradas e, ao mesmo tempo, transformar-se-iam em condições imprescindíveis para que os trabalhadores pudessem manter-se ativos e ser incluídos como força-de-trabalho apta a ser mercadorizada. A característica básica é a flexibilidade (tudo que pode implicar esse termo) e saúde, entendidas no sentido restrito de sua condição para sobreviver num mercado globalizado e competitivo (Silva, 2001, p. 79).

Se essa análise, ao incorporar elementos críticos pelo viés da mercantilização do corpo na sociedade, não pode ser desconsiderada, ela deve, ao menos, passar por um crivo analítico mais rigoroso. O corpo-mercadoria, distante da produção, é o ponto central da questão, o que faz a relação corporeidade e trabalho ser secundariamente contemplada:

A tão decantada dignidade do trabalho vai submetendo-se aos avanços tecnológicos e à ampliação da mais-valia. O corpo que outrora era valorizado em função da moral do trabalho, hoje, precisa incorporar as características da tecnologia para subsistir; sua valorização dá-se muito mais pela sua inclusão na esfera da circulação e ao paralelo afastamento 
da esfera da produção; a moral do consumo é que o valoriza (Silva, 2001, p. 79). (Sem grifos no original)

Nozaki (1999), ao refletir sobre a regulamentação profissional da Educação Física, deteve-se sobre as transformações contemporâneas no mundo do trabalho e suas conseqüências para essa dimensão educativa. Em primeiro lugar, há que se notar que esse autor posiciona-se criticamente quanto às análises que são feitas em Sociologia do Trabalho e na área de Trabalho e Educação. O problema é quando as mediações entre as constatações críticas dessas áreas são transplantadas para as análises pedagógicas sobre o corpo:

Levando-se em conta o novo modelo de qualificação para o mundo do trabalho imposto pela globalização, percebemos a clara importância de algumas disciplinas escolares estratégicas ao enquadramento do trabalhador. Seriam elas disciplinas que interagiriam na capacidade de raciocínio abstrato, que apostariam na formação para a interação em grupo, e que tentariam dar o aporte funcional dos conhecimentos mais recentemente desenvolvidos no campo tecnológico (Nozaki, 1999, p. 06).

Disso resulta que disciplinas tais como a Educação Artística e a Educação Física, passariam a ser vistas como "descartáveis" (p.06), como "elementos de luxo" (p.07), como "atividades esporádicas" (p.07) e seriam "oferecidas de modo extracurricular" (NOZAKI, 1999, p. 07). Essas constatações, no entender do autor, que apresenta suas considerações verificando nelas um modo de embate contra as "estratégias neoliberais", visam a defender a disciplina de "vários ataques no âmbito das políticas públicas educacionais, alguns de caráter geral, que aviltam todos os trabalhadores da educação sem distinção, por outro lado, também sobre um particular ataque, que desobrigaria sua presença no ensino formal..." (1999, p.08). Para Nozaki (1999), as transformações do mundo do trabalho, ao se encaminharem para a demanda de um trabalhador mais intelectualizado, estariam dispensando a Educação Física pelo fato de ela lidar com a dimensão corporal e não intelectual da educação. É o que defende também Bracht (1999):

Parece que a visão neotecnicista (economicista) de educação, que enfatiza a preparação do neotecnicista (economicista) de educação, que enfatiza a preparação do cidadão para o mercado do trabalho, dadas as mudanças tecnológicas do processo produtivo, pode prescindir hoje da EF e não lhe reserva nenhum papel relevante o suficiente para justificar o investimento público... (p. 82).

Aproximando-se da temática desta investigação, também de forma secundária, Ortigara (2001) reflete sobre a necessidade e a importância da obra de Lukács. O que se observa nas análises feitas por Ortigara (2001), é a ausência de uma reflexão das correntes transformações no mundo do trabalho e seus impactos na configuração corporal humana, sobre as quais as reflexões lukacsianas apresentam possibilidades.

Dos trabalhos pesquisados, o estudo de Silva (1996), é o que mais elabora suas intenções enxergando a questão do corpo e da educação, pela análise do trabalho. Afirmar sua importância, por sua vez, não quer dizer a não existência de limites que, ao serem pontuados, evidenciam a importância do estudo de Silva (1996). A autora parte da seguinte constatação: 
Ao se fazer uma rápida leitura da história da educação e ao analisarmos as várias tendências que a constituíram, seria possível verificar a existência do vínculo da Educação Física ao trabalho produtivo, seja através de sua ação pedagógica ou através dos diferentes conteúdos que se homogeneizaram ao longo de sua existência. [...] Ela contribuiu tanto na domestificação do corpo, como também ideologicamente, no sentido de reprimir, dominar e exaurir aquelas energias vitais, que intervêm nas construções "mentais" e na "aprendizagem cognitiva" (Silva, 1996, p. 11).

Tendo por base esse ponto de partida, a autora constrói uma narrativa sobre a instrumentalização funcionalista do corpo, as influências do espírito cartesiano e positivista e do paralelismo que há entre o "espírito do mundo produtivo" e as características educativas com as quais é tratado o corpo na vida cotidiana, no esporte e nas aulas de Educação Física. Com isso à frente, a autora conclui:

[...] temo que considerar que, com a atual organização do trabalho e com os avanços tecnológicos, as tarefas profissionais não têm exigido uma ação corporal tão desgastante. Assim, a preocupação dos responsáveis pelo processo educativo tem se deslocado do treinamento do corpo para o trabalho e se centrado no treinamento da inteligência. $O$ controle corporal do trabalhador tem que ser garantido através do treinamento do corpo para as atividades físicas, esportivas e de lazer, pois, com o taylorismo, a tarefa de controle do corpo humano foi assumida, prioritariamente, pelo próprio processo produtivo, através de sua organização. Com a centralidade das preocupações sendo transferidas para o produto do movimento humano, a tarefa de controle da gestualidade e da motricidade humana está sendo transferida para outras instituições, tais como, os meios de comunicação de massa e as atividades de Educação Física. [...] O sistema produtivo e econômico continua definindo as ações corporais que lhes são úteis, trocando os protagonistas deste processo, mas persistindo no entendimento de que a racionalização e a eficiência não podem existir sem a repressão do corpo (Silva, 1996, p. 95).(Sem grifos no original)

Há que se notar nas duas passagens idéias contraditórias servindo ao processo de relação entre a corporeidade e o trabalho. Em primeiro lugar, na passagem acima, a autora afirma que o taylorismo cuidou da formação física dos trabalhadores pela força das circunstâncias e não por um processo conscientemente pedagógico, tal qual afirmado na passagem anterior, em que a autora afirma a importância da educação física na "educação" do movimento produtivo. Em segundo lugar, salta aos olhos o fato de essas considerações chegarem a um resultado oposto daquele comentado na análise do trabalho de Nozaki (1999) e Bracht (1999). Se os autores, de um lado, afirmam que na atualidade os conteúdos da Educação Física perdem importância devido ao predomínio intelectual do trabalho, Silva (1996), de outro, defende a existência de uma "terceirização" da "tarefa educativa" (p.95) do processo produtivo, redundando em uma maior relevância da disciplina no processo.

Tal tipo de posicionamento, baseado nesse modo de entender o relacionamento da corporeidade com o processo de trabalho, acaba por resultar em um dilema que Silva (1996) define como um dos seus principais resultados: 


\begin{abstract}
Assim, o que se pode verificar é que a Educação Física encontrase diante de um grande dilema, pois precisa definir se estabelece um atrelamento maior com o sistema produtivo (fortemente vinculado ao modelo empresarial e industrial) ou rompe, de uma vez por todas, com ele. No entanto, é preciso notar que, se a Educação Física mantiver uma ligação mais direta com a perspectiva do sistema produtivo e do mercado de trabalho, inevitavelmente, estará sendo co-responsável pelos mecanismos de exploração e alienação do trabalhador, visto que, no embate entre essas práticas e uma educação emancipadora e autônoma de construção da cidadania, as primeiras têm-se mostrado historicamente vencedoras (Silva, 1996, p.106). (Sem grifos no original)
\end{abstract}

O que autora defende, ao propor a discussão da corporeidade com o mundo do trabalho, é um distanciamento dos valores inerentes a esse mundo para uma aproximação mais cuidadosa do mundo do lazer, da fruição, esses, sim, capazes de proporcionar à Educação Física a capacidade de viabilizar práticas pedagógicas que se coadunem com o movimento no sentido da ação e não do labor, tal qual a tipologia proposta por Arendt (2005); um caminho semelhante ao adotado por Bracht (1992). A forma como o mundo do trabalho é considerado no estudo de Silva (1996), faz com que o vínculo entre Educação Física, corpo e o trabalho seja posto de lado.

Para a Educação Física, então, verificamos que a discussão sobre a corporeidade e os atuais processos de trabalho, pode se configurar em mais um espaço onde subsídios para uma crítica mais efetiva da disciplina e sua relação com os desafios históricos do capitalismo é passível ser buscada. Ainda que não neguemos a importância desses estudos, a contradição acima apresentada entre os posicionamentos de Nozaki (1999)/Bracht (1999) e Silva (1996) sobre o atual papel da Educação Física, bem como a forma com a qual o trabalho é considerado nas análises de Bracht (1992) e Silva (2001), leva-nos a notar que tanto a maneira de criticar como a de defender a necessidade de se enxergar o corpo pelo trabalho, precisam ser problematizados.

\title{
CONCLUSÕES
}

O debate sobre a importância da categoria trabalho, que para alguns é reflexo das limitações do "paradigma da produção" ou da constatação do "fim do trabalho", pode ser tomado também como uma ocasião de fortalecimento de uma análise que privilegie e contemple a importância epistemológica e histórica do fato de os homens produzirem coletivamente sua existência.

Neste ínterim, a validade da categoria trabalho, tomada na acepção dada por Marx (1994) e desenvolvida por Lukács $(1979,2004)$ e Kosik (1970, 2003), está em permitir o constante trânsito entre atividade laboral e modo de produção, entre indivíduo e sociedade, entre consciência e corpo. Kosik (2003) sintetiza da seguinte maneira, esse posicionamento:

Por sua essência e universalidade, a práxis revela o segredo do homem como um ser onto-criador, que produz a realidade (humana e social) e, conseqüentemente, é capaz de compreender e explicar a realidade (humana e extra-humana, ou seja, total). A práxis do homem é a unidade ativa do homem e do mundo, da matéria e o espírito, do sujeito e do 
objeto, do produto e do produtor, essa unidade ativa se reproduzindo historicamente, ou seja, se renovando e se reconstituindo constantemente na prática (p.151).

Na área de educação física, porém, a crítica à importância do trabalho se dá baseada no entendimento de que o trabalho humano é ou físico ou intelectual. Ao apressadamente assumirem que, com as "novas tecnologias", o processo de trabalho passa a ser guiado pela "inteligência", concluem, então, que o trabalho perde sua utilidade explicativa ou fomentadora de questões. Tendo por base as reflexões de Lukács (2004), porém, notamos que os dualismos que sustentam o corrente entendimento que a área de Educação Física tem sobre o trabalho, ocorrem justamente nas imposições colocadas pela atividade laboral, na execução do dado teleológico que com o sedimentar do trabalho acaba por proporcionar a condição para os homens pensarem a necessidade de haver um domínio da consciência em relação corpo.

Evidenciando que a filosofia é uma atividade também prática, Lukács (2004) vê a questão da visão sobre o próprio homem em que o corpo, diferentemente do que ocorre no reino animal, não dita os ritmos e as atitudes, mas, sim, a consciência, como construção historicamente mediada no e pelo trabalho. Para ele, não só na religião, mas também na filosofia a questão da unidade ou dualidade do homem é tratada de forma limitada. Em primeiro lugar, trata-se de não desconsiderar que em determinado momento da história, com um determinado desenvolvimento das forças produtivas, é compreensível que a indissolubilidade humana entre fazer e pensar, demonstrada no trabalho, seja vista como predomínio da consciência sobre o corpo. É uma tensão entre aparência e essência que só socialmente pode ser compreendida em seu relacionamento, afinal existe "aqui uma irrevogável unidade objetivo-ontológica, uma impossibilidade de que exista um ser da consciência sem que esteja dado, ao mesmo tempo, um ser do corpo" (p.158).

E continua o filósofo húngaro:

[...] independência objetivamente ontológica da alma a respeito do corpo, só se baseia em uma suposição não fundada, em uma consideração que isola e abstrai essa alma do processo global, mas a atuação autônoma da consciência, a essência das posições teleológicas - que parte de semelhante atuação - o controle consciente da realização de tais posições etc, são fatos objetivos da ontologia do ser social. Se, pois, a consciência concebe sua própria autonomia a respeito do corpo como uma verdade ontologicamente absoluta, não erra na fixação imediatamente intelectual do fenômeno (p.159-160).

O posicionamento de Lukács (2004) sobre a dualidade corpo e consciência, mediada pelo trabalho, não desconsidera que essa questão está intimamente relacionada com os desenvolvimentos sociais do próprio trabalho, assim como com a luta-de-classes a partir de um certo momento da história humana. Ele defende que essa questão tem uma base social e acaba captando tendências atuais de hipertrofia da consciência frente ao corpo (o que dá a base para o grande impacto que as pesquisas sobre o corpo tem nas ciências sociais e filosofia) justamente no momento em que alguns setores da ciência criticam a idéia de uma consciência autônoma:

Só quando a sociedade se diferencia tão amplamente que o homem configura individualmente sua vida como significativa ou a abandona como sem sentido, surge este problema como algo universal e, com ele, nasce um aprofundamento da consideração da "alma" como algo 
autônomo, e agora não mais somente frente ao corpo, senão também frente aos próprios afetos espontâneos (p.161).

A relação linear entre trabalho e educação do corpo, a que justifica a idéia de que a educação física é necessária à medida que os processos produtivos existam e sejam fisiologicamente exigentes, é passível de crítica. De um lado, temos os estudiosos que defendem o fato de o trabalho estar se tornando baseado na inteligência, dispensando assim a corporeidade humana, não podendo ser o trabalho utilizado como fonte de questões para essas questões educativas. De outro, temos, por exemplo, Gleyse (1995), que ao enxergar uma "cognomorfose" do trabalho, percebe esse mesmo processo na Educação Física pela "psicologização" do corpo.

A história do pensamento educacional mostra que a consideração da educação corporal esteve presente nos mais variados modos de produção, sempre relacionada com o amplo processo de produção e reprodução social sem ater-se a procedimentos produtivos específicos. Do amplo leque de autores que deixam clara essa idéia, Fernando de Azevedo (1915) é um dos mais incisivos quando, já no início do século XX, afirmava que para os problemas da sua sociedade, o cérebro precisava mais do músculo que o próprio braço. Essa afirmação contrasta radicalmente com o comum entendimento de que, se os processos produtivos demandam características relacionadas ao pensamento, ao simbólico, a educação do corpo e mesmo o corpo estariam superados, ou que somente neste momento o corpo passaria a ser visto também como uma das origens do conhecimento e da moral, e não somente como energia, movimento e "trabalho".

A tensão histórica entre a ausência e a presença do relacionamento entre corpo, trabalho e educação, acaba por evidenciar que as mediações entre trabalho e educação na atualidade são mais numerosas e complexas do que foram no momento de Mosso e Demeny, como mostra Rabinbach (1992).

No que tange à Educação Física, vimos que a consideração da categoria trabalho, tal como analisada neste estudo, problematiza a oposição observada entre as idéias de Nozaki (1999) e Bracht (1999), que vêem uma perda de importância da disciplina, e o posicionamento de Silva (1996) e Bracht (1992), que enxergam exatamente o contrário como resultado dos correntes reordenamentos do capitalismo, defendendo, então, um afastamento das questões educativas das do mundo do trabalho. A luta contra reducionismos simplistas e mecânicos, assim, deveria impulsionar as pesquisas sobre a questão da relação entre corpo, trabalho e educação na atualidade. Não o seu contrário, como sugere a grande maioria das análises que pretendem compreender as transformações da atualidade e seus impactos no entendimento sobre as práticas pedagógicas em Educação Física.

\section{REFERÊNCIAS}

ARENDT, H. Condition de l'homme moderne. Paris : Pocket, 2005.

AZEVEDO, F. de. A poesia do corpo. Bello Horizonte: Imprensa Official do Estado de Minas, 1915.

BRACHT, V. Educação física e aprendizagem social. Porto Alegre: Magister, 1992.

BRACHT, V. A constituição das teorias pedagógicas da educação física. Cadernos Cedes, n. 48, p. 69-88, 1999. 
GLEYSE, J. Archéologie de l'éducation physique au XXe siècle en France. Paris : Presse Universitaire de France, 1995.

KOSIK, K. La dialectique du concret. Paris : François Maspero, 1970.

KOSIK, K. La crise des temps modernes : dialectique de la morale. Paris : Les Éditions de la Passion, 2003.

LESSA, S. O mundo dos homens : trabalho e ser social. São Paulo: Boitempo Editorial, 2002.

LUKÁCS, G. Ontologia do ser social: os princípios ontológicos fundamentais de Marx.

São Paulo: Livraria Editora Ontologia do ser social Ciências Humanas, 1979.

LUKÁCS, G. Ontologia del ser social: el trabajo. Buenos Aires: Herramienta, 2004.

MARX, K. O capital: crítica da economia política. 14.ed. Rio de Janeiro: Editora Bertrand Brasil, 1994, v. 1, livro 1.

NOZAKI, H. O mundo do trabalho e o reordenamento da educação física brasileira.

Revista da Educação Física da UEM. Maringá: Universidade Estadual de Maringá, v. 10, n. 1, p. 3-12, 1999.

ORTIGARA, V. Ausência sentida nos estudos em educação física: a determinação ontológica do ser. 2002. 219p. (Tese de Doutorado. Faculdade de Educação, Universidade Federal de Santa Catarina).

RABINBACH, A. The human motor: energy, fatigue and the origins of modernity. Los Angeles: University of California Press, 1992.

SILVA, M. R. S. da. A educação física, o corpo e o movimento humano na perspectiva do mundo do trabalho. 1996. 118p. (Dissertação de Mestrado. Pós-graduação em Ciências do Movimento. Universidade Federal do Rio Grande do Sul) Porto Alegre.

SILVA, A. M. Corpo, ciência e mercado: reflexões acerca da gestação de um novo arquétipo da felicidade. Campinas- SP, Florianópolis, SC: Autores Associados: Editora da UFSC, 2001.

\footnotetext{
${ }^{1}$ Sobre a questão do trabalho em Lukács, apoiamo-nos na obra de Lessa (2002).
}

Artigo recebido em: 04/08/08

Aprovado para publicação em: 05/08/09 